\title{
PERMASALAHAN AUTOKORELASI PADA ANALISIS REGRESI LINIER SEDERHANA
}

\author{
NADIA UTIKA PUTRI, MAIYASTRI, HAZMIRA YOZZA \\ Program Studi Matematika, \\ Fakultas Matematika dan Ilmu Pengetahuan Alam, Universitas Andalas, \\ Kampus UNAND Limau Manis Padang, Indonesia, \\ utika.nadiya@gmail.com,hyozza@gmail.com
}

\begin{abstract}
Abstrak. Pada analisis regresi linier sederhana model yang terbentuk harus memenuhi beberapa asumsi yang dikenal dengan asumsi linier klasik. Dalam asumsi linier klasik dinyatakan bahwa tidak terdapat korelasi antar galat yang disebut autokorelasi. Bila autokorelasi terjadi pada model regresi linier sederhana maka pengaruhnya terlihat pada penduga parameter yang tidak lagi BLUE (Best Linear Unbiased Estimator), yaitu penduga tidak bias dan linier, namun tidak lagi memiliki ragam yang minimum. Pengaruh autokorelasi juga dilihat menggunakan simulasi Monte Carlo. Simulasi Monte Carlo menggunakan nilai bias dan Kuadrat Tengah Galat (KTG) dengan berbagai ukuran sampel dan koefisien autokorelasi yang bervariasi. Hasil simulasi menunjukkan semakin besar ukuran sampel maka bias dan KTG semakin kecil dan semakin besar nilai koefisien autokorelasi maka bias dan KTG semakin besar.
\end{abstract}

Kata Kunci: Autokorelasi, BLUE (Best Linear Unbiased Estimator), Bias, Kuadrat Tengah Galat (KTG).

\section{Pendahuluan}

Analisis regresi merupakan teknik statistika yang digunakan untuk mengetahui hubungan antara variabel bebas $(\mathrm{X})$ dengan variabel terikat $(\mathrm{Y})$. Pada analisis regresi terdapat beberapa asumsi yang harus dipenuhi yang dikenal dengan asumsi linier klasik yang menyatakan bahwa galat $\varepsilon_{i}, i=1,2, \ldots, n$ merupakan suatu peubah acak yang saling bebas yang menyebar menurut sebaran normal dengan nilai tengah nol dan ragam $\sigma^{2}$. Dengan kata lain, $\varepsilon_{i} \hat{b s i} N\left(0, \sigma^{2}\right)$.

Salah satu pelanggaran asumsi linier klasik yaitu terdapat serial korelasi antar galat yang dinamakan autokorelasi. Autokorelasi terjadi pada data runtun waktu. Jika autokorelasi terjadi pada model regresi linier maka hal yang menarik untuk diteliti adalah pengaruh autokorelasi tersebut terhadap model regresi linier.

Pengaruh autokorelasi terhadap model dapat diteliti melalui berbagai pendekatan. Pendekatan secara teori biasanya dilakukan untuk tipe autokorelasi yang paling sederhana yaitu tipe autokorelasi tingkat satu pada galat. Sedangkan untuk tipe autokorelasi yang lebih bervariasi seperti nilainya yang semakin besar dan ukuran sampel yang berbeda-beda pengaruh autokorelasi terhadap model dapat menggunakan Simulasi Monte Carlo. 


\section{Analisis Regresi Linier}

\subsection{Metode Kuadrat Terkecil Pada Analisis Regresi Linier Sederhana [2]}

Menurut [2], analisis regresi linier sederhana adalah analisis regresi yang dilakukan untuk data dengan satu variabel terikat dan satu variabel bebas. Model regresi linier sederhana suatu populasi dapat dinyatakan sebagai

$$
y_{i}=\beta_{0}+\beta_{1} x_{i}+\varepsilon_{i} \quad ; i=1,2, \ldots, n
$$

dengan $y_{i}$ merupakan nilai variabel terikat untuk pengamatan ke-i, $x_{i}$ merupakan nilai variabel bebas untuk pengamatan ke-i, $\beta_{0}, \beta_{1}$ merupakan parameter regresi dan $\varepsilon_{i}$ merupakan nilai galat untuk pengamatan ke-i.

Metode kuadrat terkecil adalah salah satu metode yang dapat digunakan untuk menduga parameter pada model regresi linier sederhana dengan meminimumkan jumlah kuadrat simpangan sehingga diperoleh

$$
\begin{aligned}
& \hat{\beta_{0}}=\bar{y}-\hat{\beta_{1}} \bar{x} \\
& \hat{\beta_{1}}=\frac{\sum_{i=1}^{n} x_{i} y_{i}-\left(\sum_{i=1}^{n} x_{i} \sum_{i=1}^{n} y_{i}\right) / n}{\sum_{i=1}^{n} x_{i}^{2}-\left(\sum_{i=1}^{n} x_{i}\right)^{2} / n}=\frac{\sum_{i=1}^{n}\left(x_{i}-\bar{x}\right)\left(y_{i}-\bar{y}\right)}{\sum_{i=1}^{n}\left(x_{i}-\bar{x}\right)^{2}}
\end{aligned}
$$

\subsection{Bias dan Kuadrat Tengah Galat}

Terdapat dua sifat yang harus dipenuhi sehingga penduga tersebut dapat dikatakan pendug terbaik yaitu penduga yang tak bias dan memiliki ragam minimum. Penduga tak bias adalah penduga yang memiliki nilai harapan yang sama dengan parameter regresi yang akan diduga. Jika ada dua penduga yang tak bias maka penduga dengan ragam yang minimum menjadi penduga yang lebih baik. Namun jika penduga tidak memenuhi kedua kriteria tersebut secara bersamaan, maka dapat dilihat dari kriteria berikut:

- Bias.

Jika $\hat{\beta}$ adalah penduga bagi $\beta$, maka bias didefinisikan sebagai

$$
\text { Bias }=E(\hat{\beta})-\beta
$$

- Kuadrat Tengah Galat (Mean Square Error).

$$
M S E=E(\hat{\beta}-\beta)^{2}
$$

Dari kedua kriteria di atas penduga yang baik adalah penduga yang memiliki bias terkecil atau kuadrat tengah galat terkecil.

\section{Metode Penelitian}

Penelitian ini dilakukan melalui studi literatur dan Simulasi Monte Carlo dengan program Minitab 14. Berikut adalah langkah-langkah simulasi yang dilakukan : 
(1) Dengan menggunakan model regresi linier sederhana $y_{i}=\beta_{0}+\beta_{1} x+\varepsilon$ tetapkan nilai untuk $\beta_{0}$ dan $\beta_{1}$ dari model regresi.

(2) Bangkitkan model regresi linier sederhana [6]

$$
y_{i}=\beta_{0}+\beta_{1} x_{i}+\varepsilon_{i} ; i=1,2, \ldots, n
$$

dengan nilai sisaan $e_{i}$ yang memiliki sifat autokorelasi. Namun, asumsi linier klasik yang lain dipenuhi yaitu nilai tengah adalah nol dan ragam konstan. Pembangkitan data dilakukan dengan cara sebagai berikut :

(a) Tetapkan $n$

(b) Tetapkan data $x_{i}=1,2, \ldots, n$

(c) Untuk melihat pengaruh autokorelasi, nilai sisaan dibangkitkan melalui model autoregresif tingkat satu (first-order autoregressive), yaitu $e_{i}=$ $\rho e_{i-1}+\delta_{i}$, untuk $i=1,2,3, \ldots, n$. Prosedur yang dilakukan adalah sebagai berikut :

i. Tetapkan $\rho$

ii. Bangkitkan secara acak $n$ nilai $\delta_{i}$ dar sebaran normal dengan nilai tengah nol dan ragam dua, $\delta_{i} N(0,2)$.

iii. Tetapkan $e_{0}=1$

iv. Hitung $e_{i}=\rho e_{i-1}+\delta_{i} ; i=1,2,3, \ldots, n$. Jadi sudah diperoleh nilai sisaan yang memiliki sifat autokorelasi tingkat satu.

(d) Hitung data $y_{i}=\beta_{0}+\beta_{1} x_{i}+\varepsilon_{i}$.

(e) Dari data $X_{i}$ dan $Y_{i}$. Duga $\beta_{0}$ dan $\beta_{1}$ yaitu $b_{0}$ dan $b_{1}$.

(f) Ulangi sebanyak $\mathrm{T}$ ulangan sehingga diperoleh $b_{0, t}$ dan $b_{1, t}$ dengan $t=$ $1,2,3, \ldots, T$.

(3) Tentukan $\overline{b_{0}}$ dan $\overline{b_{1}}$

$$
\overline{b_{0}}=\frac{\sum_{t=1}^{T} b_{0, t}}{T}, \overline{b_{1}}=\frac{\sum_{t=1}^{T} b_{1, t}}{T}
$$

(4) Hitung bias untuk masing-masing parameter regresi

1 Untuk $\beta_{0} ;$ bias $=\overline{b_{0}}-\beta_{0}$

2 Untuk $\beta_{1}$; bias $=\overline{b_{1}}-\beta_{1}$

(5) Hitung kuadrat tengah galat, $M S E=\frac{(\text { bias })^{2}}{T}$

(6) Lakukan untuk beberapa skenario berikut: $n_{1}=10, n_{2}=15, n_{3}=20, n_{4}=$ $25, n_{5}=30, n_{6}=50, n_{7}=75$, dan $n_{8}=100$ dengan nilai $\rho$ sebagai berikut: $\pm 0,1, \pm 0,3, \pm 0,5, \pm 0,7, \pm 0,9$.

\section{Analisis dan Pembahasan}

Autokorelasi adalah penyimpangan pada asumsi linier klasik dimana terjadi korelasi antara galat pengamatan ke i dengan pengamatan ke j. Pada model regresi linier sederhana untuk data sampel

$$
y_{i}=\widehat{\beta}_{0}+\widehat{\beta}_{1} x_{i}+\varepsilon_{i}
$$

atau dengan bentuk matriks

$$
Y=X \widehat{\beta}+e
$$


autokorelasi terjadi bila terdapat kondisi dimana

$$
\operatorname{cov}\left(e_{i}, e_{j}\right) \neq 0 \quad i \neq j
$$

Penyebab terjadinya autokorelasi diantara galat adalah Inersia atau kelembaman, bias dalam spesifikasi, keterlambatan ( Lag), manipulasi data.

\subsection{Pengaruh Autokorelasi}

Suatu model regresi linier harus memenuhi asumsi linier klasik. Untuk memenuhi asumsi tersebut autokorelasi harus dihindari. Pada sub bab ini akan dipaparkan pengaruh autokorelasi terhadap penduga. Pada model autoregresif tingkat satu (first-order autoregressive) yang memiliki persamaan sebagai berikut

$$
e_{i}=\rho e_{i-1}+\delta_{i} \quad-1<\rho<1
$$

Nilai $\rho$ pada Persamaan (4.4) merupakan koefisien autokorelasi. Jika $\rho$ mendekati -1 atau 1, maka sifat autokorelasi semakin substansial. Komponen $\delta_{i}$ memenuhi asumsi model regresi linier klasik berikut:

$$
\begin{gathered}
E\left(\delta_{i}\right)=0 ; \operatorname{Var}\left(\delta_{i}\right)=\sigma_{\delta}^{2} \\
\operatorname{cov}\left(\delta_{i}, \delta_{j}\right)=0 \quad i \neq j \text { untuk semua } i
\end{gathered}
$$

Asumsi di atas merupakan model autoregresif tingkat pertama AR(1) yang menunjukkan bahwa $e_{i}$ yang bergantung pada $e_{i-1}$. Bentuk lengkap dari AR(1) adalah:

$$
\begin{aligned}
e_{i} & =\rho e_{i-1}+\delta_{i} \\
e_{i-1} & =\rho e_{i-2}+\delta_{i-1} \\
e_{i-2} & =\rho e_{i-3}+\delta_{i-2} \\
\vdots & \\
e_{i-r} & =\rho e_{i-(r+1)}+\delta_{i-r}
\end{aligned}
$$

maka,

$$
\begin{aligned}
e_{i} & =\rho\left(\rho e_{i-2}+\delta_{i-1}\right)+\delta_{i} \\
& =\rho^{2} e_{i-2}+\rho \delta_{i-1}+\delta_{i} \\
& =\rho^{2}\left(\rho e_{i-3}+\delta_{i-2}\right)+\rho \delta_{i-1}+\delta_{i} \\
& =\rho^{3} e_{i-3}+\rho^{2} \delta_{i-2}+\rho \delta_{i-1}+\delta_{i} \\
& \vdots \\
& =\delta_{i}+\rho \delta_{i-1}+\rho^{2} \delta_{i-2}+\rho^{3} \delta_{i-3}+\ldots
\end{aligned}
$$

sehingga,

$$
e_{i}=\sum_{r=0}^{\infty} \rho^{r} \delta_{i-r}
$$

Dari Persamaan (9) maka nilai tengah, ragam dan koragam dari galat berkorelasi sebagai berikut: 
$30 \quad$ Nadia Utika dkk.

(1) Nilai Tengah

$$
\begin{aligned}
E\left(e_{i}\right) & =E\left(\sum_{r=0}^{\infty} \rho^{r} \delta_{i-r}\right) \\
& =\sum_{r=0}^{\infty} \rho^{r} E\left(\delta_{i-r}\right)
\end{aligned}
$$

Diketahui $E\left(\delta_{i}\right)=0$ untuk semua $t$, maka $E\left(\delta_{i-r}\right)=0$, maka

$$
E\left(e_{i}\right)=0 \text {. }
$$

(2) Ragam

$$
E\left(e_{i}^{2}\right)=E\left(\sum_{r=0}^{\infty} \rho^{r} \delta_{i-r}\right)^{2}
$$

karena $\operatorname{cov}\left(\delta_{i}, \delta_{j}\right)=0$, maka

$$
\begin{aligned}
E\left(e_{i}^{2}\right) & =\sum_{r=0}^{\infty}\left(\rho^{r}\right)^{2} E\left(\delta_{i-r}\right)^{2} \\
& =\sum_{r=0}^{\infty} \rho^{2 r} \sigma_{\delta}^{2} \\
& =\sigma_{\delta}^{2}\left(1+\rho^{2}+\rho^{4}+\cdots\right)
\end{aligned}
$$

jadi, ragam adalah :

$$
\sigma_{e}^{2}=\frac{\sigma_{\delta}^{2}}{1-\rho^{2}}
$$

(3) Koragam $E\left(e_{i} e_{i-1}\right)=E\left(\left\{\delta_{i}+\rho \delta_{i-1}+\rho^{2} \delta_{i-2}+\cdots\right\}\left\{\delta_{i-1}+\rho \delta_{i-2}+\rho^{2} \delta_{i-3}+\cdots\right\}\right)$

$$
=E\left(\delta_{i}\left\{\delta_{i-1}+\rho \delta_{i-2}+\rho^{2} \delta_{i-3}+\cdots\right\}+\rho\left(\delta_{i-1}+\rho \delta_{i-2}+\cdots\right)^{2}\right)
$$

Karena $\operatorname{cov}\left(\delta_{i}, \delta_{j}\right)=0 \quad ; i \neq j$, maka

$$
\begin{aligned}
E\left(e_{i} e_{i-1}\right) & =\rho E\left(\left(\delta_{i-1}+\rho \delta_{i-2}+\cdots\right)^{2}\right) \\
& =\rho E\left(\delta_{i-1}^{2}+\rho^{2} \delta_{i-2}^{2}+\cdots\right) \\
& =\rho\left(E\left(\delta_{i-1}^{2}\right)+\rho^{2} E\left(\delta_{i-2}^{2}\right)+\cdots\right) \\
& =\rho\left(\sigma_{\delta}^{2}\left(1+\rho^{2}+\rho^{4}+\cdots\right)\right) \\
& =\rho \frac{\sigma_{\delta}^{2}}{1-\rho^{2}} \\
& =\rho \sigma_{e}^{2}
\end{aligned}
$$

Dengan cara yang sama, diperoleh

$$
\begin{aligned}
E\left(e_{i} e_{i-2}\right) & =\rho^{2} \sigma_{e}^{2} \\
E\left(e_{i} e_{i-3}\right) & =\rho^{3} \sigma_{e}^{2} \\
\vdots & \\
E\left(e_{i} e_{i-s}\right) & =\rho^{s} \sigma_{e}^{2} \text { untuk } s \neq i .
\end{aligned}
$$


Jika ragam dan koragam disusun dalam bentuk matriks maka diperoleh :

$$
E e e^{T}=V=\sigma_{e}^{2}\left(\begin{array}{ccccc}
1 & \rho & \rho^{2} & \cdot s & \rho^{n-1} \\
\rho & 1 & \rho & \cdot s & \rho^{n-2} \\
\vdots & \vdots & \vdots & \vdots & \vdots \\
\rho^{n-1} & \rho^{n-2} & \rho^{n-3} & \cdot s & 1
\end{array}\right)
$$

Penduga yang diperoleh memiliki karakteristik bersifat linier dan tidak bias. Hal ini dibuktikan pada bagian berikut :

Pertama akan diduga bahwa penduga tersebut bersifat linier. Berdasarkan persamaan (4.2) diperoleh :

$$
\begin{aligned}
\widehat{\beta} & =\left(X^{T} X^{-1}\right)\left(X^{T} Y\right) \\
& =\left(X^{T} X^{-1}\right) X^{T}(X \beta+e) \\
& =\left(X^{T} X^{-1}\right) X^{T} X^{b}+\left(X^{T} X^{-1}\right) X^{T} e \\
& =\beta+\left(X^{T} X^{-1}\right) X^{T} e
\end{aligned}
$$

Dari persamaan (4.6) terlihat bahwa $\widehat{\beta}$ berifat linier terhadap $e$, jadi $\widehat{\beta}$ bersifat linier. Selanjutnya dengan nilai sisaan yang berkorelasi diperoleh:

$$
\begin{aligned}
E(\widehat{\beta}) & =E\left[\beta+\left(X^{T} X\right)^{-1} X^{T} e\right] \\
& =E(\beta)+\left(X^{T} X\right)^{-1} X^{T} E(e) \\
& =\beta
\end{aligned}
$$

dari persamaan (4.7) terlihat bahwa $\widehat{\beta}$ penduga tak bias dari $\beta$.

Selanjutnya akan ditunjukkan untuk nilai sisaan yang berkorelasi tidak memiliki ragam minimum. Apabila ragam dari $\widehat{\beta}$ memiliki nilai sisaan yang berkorelasi maka

$$
\operatorname{Var}(\widehat{\beta})=E\left[\{\widehat{\beta}-E(\widehat{\beta})\}\{\widehat{\beta}-E(\widehat{\beta})\}^{T}\right] .
$$

Berdasarkan persamaan (4.2) diperoleh

$$
\begin{aligned}
\operatorname{Var}(\widehat{\beta}) & =E\left[\left(X^{T} X\right)^{-1} X^{T} e e^{T} X\left(X^{T} X\right)^{-1}\right] \\
& =\left(X^{T} X\right)^{-1} X^{T} E\left(e e^{T}\right) X\left(X^{T} X\right)^{-1} .
\end{aligned}
$$

Jadi, berdasarkan Persamaan (4.5) diperoleh

$$
\operatorname{Var}(\widehat{\beta})=\left(X^{T} X\right)^{-1} X^{T} V X\left(X^{T} X\right)^{-1}
$$

Untuk pembuktian selanjutnya, akan dilakukan transformasi variabel $Y_{i}$ dan $X_{i}$ dengan model regresi linier sederhana.

$$
Y_{i}=\widehat{\beta}_{0}+\widehat{\beta}_{1} X_{i}+e_{i},
$$

menjadi

$$
y_{i}=\widehat{\beta}_{1} x_{i}+e_{i}
$$

dengan

$$
\begin{array}{r}
y_{i}=Y_{i}-\widehat{Y} \\
x_{i}=X_{i}-\widehat{X} .
\end{array}
$$


Ragam untuk Persamaan (4.7) yang memiliki nilai sisaan yang berkorelasi adalah

$$
\begin{aligned}
\operatorname{Var}(\widehat{\beta}) & =\left(X^{T} X\right)^{-1} X^{T} V X\left(X^{T} X\right)^{-1} \\
& =\frac{1}{\sum_{i=1}^{n} x_{i}^{2}} \sigma_{e}^{2}\left(x_{1} x_{2} \cdots x_{n}\right)\left(\begin{array}{ccccc}
1 & \rho & \rho^{2} & \cdots & \rho^{n-1} \\
\rho & 1 & \rho & \cdots & \rho^{n-2} \\
\vdots & \vdots & \vdots & \vdots & \vdots \\
\rho^{n-1} & \rho^{n-2} & \rho^{n-3} & \cdots & 1
\end{array}\right)\left(\begin{array}{c}
x_{1} \\
x_{2} \\
\vdots \\
x_{n}
\end{array}\right) \frac{1}{\sum_{i=1}^{n} x_{i}^{2}} \\
& =\frac{\sigma_{e}^{2}}{\sum_{i=1}^{n}}\left[1+2 \rho \frac{\sum_{i=1}^{n-1} x_{i} x_{i+1}}{\left(\sum_{i=1}^{n} x_{i}^{2}\right)^{2}}+2 \rho^{2} \frac{\sum_{i=1}^{n-2} x_{i} x_{i+2}}{\left(\sum_{i=1}^{n} x_{i}^{2}\right)^{2}}+\cdot s+2 \rho^{n-1} \frac{x_{1} x_{n}}{\left(\sum_{i=1}^{n} x_{i}^{2}\right)^{2}}\right]
\end{aligned}
$$

yang selanjutnya dinotasikan dengan $\operatorname{Var}(\widehat{\beta})_{A R(1)}$ yaitu ragam bila galat berkorelasi dengan model autoregresif tingkat pertama. Sehingga diperoleh

$$
\operatorname{Var}(\widehat{\beta})_{A R(1)}>\operatorname{Var}(\widehat{\beta})
$$

Ragam pada penduga metode kuadrat terkecil dengan galat yang berkorelasi bukan ragam yang minimum lagi.

\subsection{Hasil Simulasi}

Pengaruh autokorelasi dilihat dengan menggunakan Simulasi Monte Carlo. Simulasi Monte Carlo menggunakan nilai bias dan MSE (mean squared error) dengan berbagai ukuran sampel $(n)$, nilai koefisien autokorelasi $(\rho)$ dan ulangan $(T)$ yang ditampilkan pada gambar-gambar berikut ini :

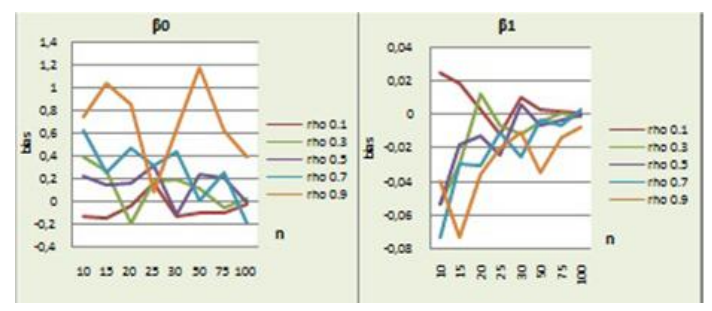

Gambar 1. Nilai bias dari $\beta_{0}$ dan $\beta_{1}$ dengan ukuran sampel yang berbeda

Gambar 1 menunjukkan nilai bias dari $\beta_{0}$ dan $\beta_{1}$ dengan ukuran sampel yang berbeda dan masing-masing garis adalah untuk nilai koefisien autokorelasi $(\rho)$ yang berbeda. Untuk nilai bias dari $\beta_{0}$ secara umum terlihat masing-masing garis bergerak untuk ukuran sampel yang semakin besar, hal yang sama juga ditunjukkan untuk nilai bias dari $\beta_{1}$ dimana terlihat masing-masing garis juga bergerak untuk ukuran sampel yang semakin besar. Hal ini menunjukkan bahwa semakin besar ukuran sampel, garis menuju ke satu nilai yaitu nol yang berarti bahwa semakin besar ukuran sampel maka bias semakin kecil.

Gambar 2 menunjukkan nilai MSE dari $\beta_{0}$ dan $\beta_{1}$ dengan ukuran sampel yang berbeda dan masing-masing garis adalah untuk nilai koefisien autokorelasi $(\rho)$ yang berbeda. Pada Gambar 2 terlihat diagram garis menunjukkan hasil yang hampir 


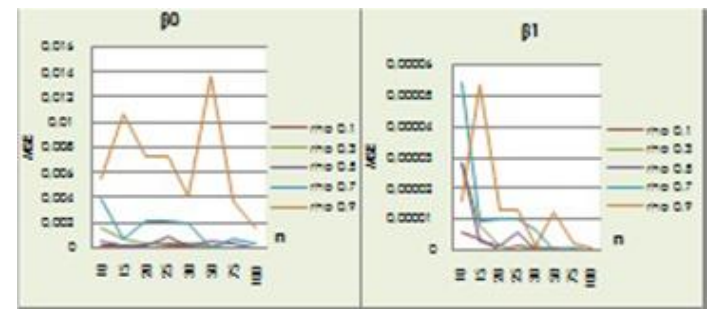

Gambar 2. Nilai MSE dari $\beta_{0}$ dan $\beta_{1}$ dengan ukuran sampel yang berbeda

sama dengan Gambar 1. Untuk nilai MSE dari $\beta_{0}$ secara umum terlihat masingmasing garis bergerak untuk ukuran sampel yang semakin besar, hal yang sama juga ditunjukkan untuk nilai MSE dari $\beta_{1}$ dimana terlihat masing-masing garis juga bergerak untuk ukuran sampel yang semakin besar. Hal ini menunjukkan bahwa semakin besar ukuran sampel, garis menuju ke satu nilai yaitu nol yang berarti bahwa semakin besar ukuran sampel maka MSE semakin kecil.

Selanjutnya akan ditunjukkan diagram garis dari tabel $T=1000$ yang ditampilkan pada Gambar 3 dan Gambar 4 berikut ini.

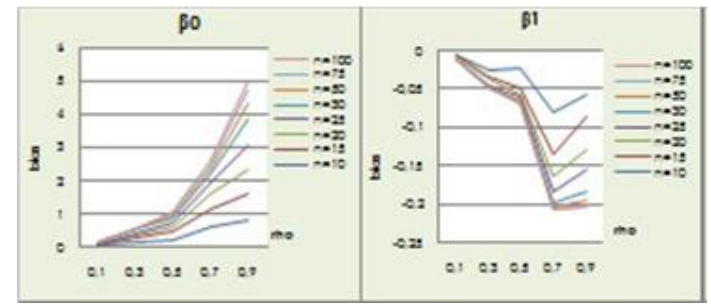

Gambar 3. Nilai bias dari $\beta_{0}$ dan $\beta_{1}$ dengan nilai $(\rho)$ yang berbeda

Gambar 3 menunjukkan nilai bias dari $\beta_{0}$ dan $\beta_{1}$ dengan nilai koefisien autokorelasi $(\rho)$ yang bernilai positif yang berbeda dan masing-masing garis adalah untuk ukuran sampel yang berbeda. Pada gambar terlihat bahwa garis mengikuti nilai koefisien autokorelasi yang semakin besar. Hal ini ditunjukkan pada nilai koefisien autokorelasi adalah 0,1 masing-masing garis menujukkan bias yang kecil dan bergerak untuk nilai koefisien autokorelasi yang semakin besar. Hal ini menunjukkan bahwa untuk nilai koefisien autokorelasi $(\rho)$ positif yang semakin besar maka maka nilai bias semakin besar. Hal yang sama juga ditunjukkan untuk nilai koefisien autokorelasi yang bernilai negatif yang berbeda.

Gambar 4 menunjukkan hasil yang hampir sama dengan Gambar 3. Gambar 4 menunjukkan nilai MSE dari $\beta_{0}$ dan $\beta_{1}$ dengan nilai koefisien autokorelasi $(\rho)$ yang bernilai positif yang berbeda dan masing-masing garis adalah untuk ukuran sampel yang berbeda. Pada gambar terlihat bahwa garis mengikuti nilai koefisien autokorelasi yang semakin besar. Hal ini ditunjukkan pada nilai koefisien autokorelasi adalah 0,1 masing-masing garis menunjukkan MSE yang kecil dan bergerak untuk nilai koefisien autokrelasi yang semakin besar. Hal ini menunjukkan bahwa untuk 


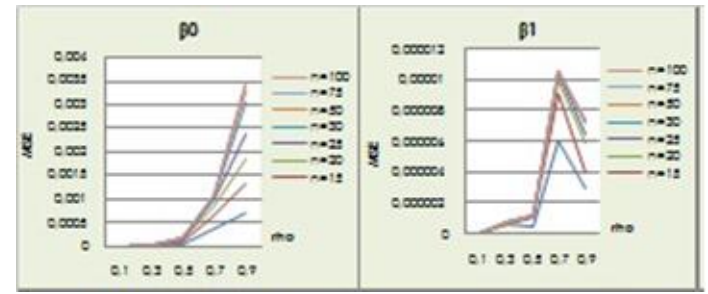

Gambar 4. Nilai MSE dari $\beta_{0}$ dan $\beta_{1}$ dengan nilai $(\rho)$ yang berbeda

nilai koefisien autokorelasi $(\rho)$ positif yang semakin besar maka maka nilai MSE semakin besar. Hal yang sama juga ditunjukkan untuk nilai koefisien autokorelasi yang bernilai negatif yang berbeda.

\section{Kesimpulan}

Autokorelasi pada model regresi linier sederhana akan mengakibatkan penduga koefisien regresi masih linier dan masih tidak bias namun ragam penduga koefisien regresi (varb) memiliki ragam yang lebih besar dari ragam penduga koefisien regresi pada model regresi linier sederhana yang tidak memiliki autokorelasi. Jadi, model regresi linier yang memiliki autokorelasi bukan merupakan penduga terbaik.

Simulasi Monte Carlo menunjukkan semakin tinggi nilai koefisien autokorelasi ( $\rho$ ) maka nilai bias dan MSE semakin besar yang berarti bahwa semakin tinggi nilai koefisien autokorelasi pengaruh autokorelasi semakin substansial. Selain itu, untuk ukuran contoh yang semakin besar $(n)$ maka nilai bias dan MSE semakin kecil.

\section{Ucapan Terima kasih}

Penulis mengucapkan terima kasih kepada pembimbing ibu Dr.Maiyastri dan ibu Hazmira Yozza M.si atas bimbingannya dalam penelitian ini. Terima kasih juga kepada ibu Izzati Rahmi H.G M.Si, ibu Dr. Susila Bahri dan Bapak Budi Rudianto M.Si yang telah memberikan masukan dan saran sehingga paper ini dapat diselesaikan dengan baik.

\section{Daftar Pustaka}

[1] Bain, L.J and Max Engelhardt. 1987. Introduction To Probability and Mathematical Statistics Second Edition. Duxbury Press, California

[2] Draper,N dan Smith. 1992. Analisis Regresi Terapan Edisi Ke-2. Gramedia, Jakarta.

[3] Gujarati, D.N. 1997. Ekonometrika Dasar. Penerbit Erlangga, Jakarta

[4] Lains, A. 2003. Ekonometrika Teori dan Aplikasi Jilid Satu. Pustaka LP3ES, Jakarta.

[5] Montgomery, D.C. 1992. Introduction To Linear Regression Analysis Second Edition. John Wiley And Son,Inc, New York 